University of Nebraska - Lincoln

DigitalCommons@University of Nebraska - Lincoln

Food and Drug Administration Papers

U.S. Department of Health and Human Services

2018

Parent Perspectives on Health and Functioning of School-Aged Adolescents With Disabilities

Gavin Colquit EdD, CAPE, CSCS

Ashley D. Walker PhD, CHES

Moya L. Alfonso PhD, MSPH

Maria Olivas MPH

Bethrand Ugwu MPH

See next page for additional authors

Follow this and additional works at: https://digitalcommons.unl.edu/usfda

Part of the Dietetics and Clinical Nutrition Commons, Health and Medical Administration Commons, Health Services Administration Commons, Pharmaceutical Preparations Commons, and the Pharmacy Administration, Policy and Regulation Commons

This Article is brought to you for free and open access by the U.S. Department of Health and Human Services at DigitalCommons@University of Nebraska - Lincoln. It has been accepted for inclusion in Food and Drug Administration Papers by an authorized administrator of DigitalCommons@University of Nebraska - Lincoln. 


\section{Authors}

Gavin Colquit EdD, CAPE, CSCS; Ashley D. Walker PhD, CHES; Moya L. Alfonso PhD, MSPH; Maria Olivas $\mathrm{MPH}$; Bethrand Ugwu MPH; and Theophile Dipita Dr, PH 


\title{
Parent Perspectives on Health and Functioning of School-Aged Adolescents With Disabilities
}

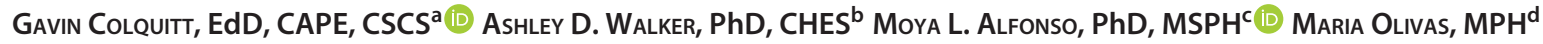 \\ Bethrand Ugwu, MPH ${ }^{\mathrm{e}}$ Theophile Dipita, DrPH
}

\section{ABSTRACT}

BACKGROUND: Youth living with disabilities are at risk of experiencing poor health outcomes. Coordinated school health programs have an opportunity to help youth with disabilities and their families through health education, health services, and community engagement. The World Health Organization developed the International Classification of Functioning, Disability, and Health (ICF) as a framework to analyze factors related to health conditions. We used the ICF to examine parental perceptions of health and function among students with disabilities living in rural and urban areas.

METHODS: We surveyed parents $(\mathrm{N}=71)$ using the parent-report versions of the Pediatric Outcomes Data Collection Instrument and Child Health and Illness Profile. From this group, parents were asked to volunteer to participate in in-depth, individual interviews $(\mathrm{N}=18)$. The interviews were audio-recorded and transcribed verbatim. Researchers used the ICF linking rules to analyze and code the transcriptions. Emergent themes were assigned numerical ICF codes.

RESULTS: There were more similarities than differences among rural and urban families. Children living with disabilities face significant environmental barriers regardless of context.

CONCLUSIONS: Schools can facilitate education to improve the quality of life of parents and families of children with disabilities. School authorities should consider the many environmental barriers both urban and rural these families face in the community. The ICF can be used as a framework for program planning for community-based, health education for this population.

Keywords: children with disabilities; child and adolescent health; school health instruction; exceptional children; health educators.

Citation: Colquitt G, Walker AD, Alfonso ML, Olivas M, Ugwu B, Dipita T. Parent perspectives on health and functioning of school-aged adolescents with disabilities. J Sch Health. 2018; 88: 676-684.

Received on August 16, 2017

Accepted on November 20, 2017

$\mathrm{T}$ he major premise of Basch" — that "healthier students are better learners" - provides a firm justification for the role of school health professionals in schools. Schools have the opportunity to improve student learning through health education, provision of health services, and community engagement. ${ }^{2}$ Coordinated school health programs can serve as a vehicle for school improvement efforts with a particular focus on at-risk populations. ${ }^{3}$

A large at-risk population in US public schools are students with disabilities. Approximately 6.5 million children attending public schools have a disability as defined by the Individuals with Disabilities Education Act (IDEA). ${ }^{4,5}$ Young people with disabilities are

\footnotetext{
aAssociate Professor, (gcolquitt@georgiasouthern.edu), Georgia Southern University, Department of Health Sciences and Kinesiology, PO Box 8076, Statesboro, GA 30460.

${ }^{\text {b} A s s o c i a t e ~ P r o f e s s o r, ~(a w a l k e r @ g e o r g i a s o u t h e r n . e d u), ~ C o m m u n i t y ~ H e a l t h ~ E d u c a t i o n ~ \& ~ B e h a v i o r, ~ J i a n n-P i n g ~ H s u ~ C o l l e g e ~ o f ~ P u b l i c ~ H e a l t h, ~ G e o r g i a ~ S o u t h e r n ~ U n i v e r s i t y, ~ P O ~ B o x ~ 8015, ~}$ Statesboro, GA 30460.

'Associate Professor, (malfonso@georgiasouthern.edu), Community Health Behavior and Education, Jiann-Ping Hsu College of Public Health, Georgia Southern University, PO Box 8015, Statesboro, GA 30460

d'Graduate Assistant, (mo01736@georgiasouthern.edu), Jiann-Ping Hsu College of Public Health, Georgia Southern University, PO Box 8015 , Statesboro, GA 30460. eGraduate Assistant, (bu00206@georgiasouthern.edu), Jiann-Ping Hsu College of Public Health, Georgia Southern University, PO Box 8015, Statesboro, GA 30460.

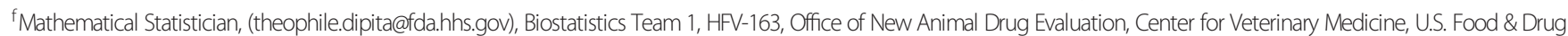
Administration, 7500 Standish Place, Rockville, MD 20855

Address correspondence to: Gavin Colquitt, Associate Professor, (gcolquitt@georgiasouthern.edu), Georgia Southern University, School of Health \& Kinesiology, PO Box 8076, Statesboro, GA 30460.
} 
at a greater risk for both poor health outcomes and other high risk behaviors. ${ }^{6-8}$ Due to these disparities, it is important to promote health equity by improving conditions of daily life for this population. This can be accomplished by addressing the lack of resources for children with disabilities within the environmental context. ${ }^{9}$ Living in rural environments typically exacerbates health disparities and in general, school-aged youth experience poorer health outcomes due to the lack of resources including recreational and health services. ${ }^{10}$

However, school-aged youth living with a disability have negative health outcomes regardless of context (urban versus rural) because availability of resources for this population is sparse. ${ }^{11}$ For this reason, public health and school health practitioners in both rural and urban areas should seek to form partnerships with health care providers to develop comprehensive programs for students with disabilities with a focus on prevention. Public schools in 49 states and the District of Columbia receive Medicaid reimbursements for health related services for students receiving special education, ${ }^{12}$ with schools required by IDEA to provide support services required for a free and appropriate, public education. Despite these supports, children with disabilities face some of their most significant barriers to participation and meaningful interaction within their environments at school and community. ${ }^{13}$ School health programming offers a vehicle to meeting the needs of these students, but few health education programs offer training specific to disability health. ${ }^{14}$ In addition, very few school-based health programs specifically target students with disabilities..$^{15}$

The definitions of disability among youth have drastically changed as is reflected in changing perceptions of child health and development. ${ }^{16}$ Indeed, functionality plays an integral role in the physical and psychological well-being of the young people with disabilities. ${ }^{17}$ In 2002, the World Health Organization (WHO) developed the International Classification of Functioning, Disability, and Health (ICF). ${ }^{18}$ The ICF was developed to catalyze the paradigm shift defining disability from a solely functional standpoint to include the complex interactions between the broader array of health conditions and contextual factors.

The ICF is a flexible framework that can serve as a planning tool for coordinated school health programs for students with disabilities and the assessment of student health needs at varying levels of specificity in multiple areas. The ICF uses 3 levels to classify functioning: (1) health condition; (2) body structure/function, participation, and activities; and (3) contextual factors (ie, environmental and personal) and continues to evolve as a tool for policymakers, researchers, and health educators. ${ }^{19}$ The focus of the ICF is how the abilities and characteristics of the individual (ie, body structure/function, participation, and activities) are affected by the health condition and mediated by the environment (Figure 1).

According to Heiman, ${ }^{20}$ children with a disability and their families experience a higher level of environmental dysfunction due to additional life stressors compared to nondisabled children and their families. Coordinated school health programs can enhance utilization of social resources and engagement thereby improving the ability of children and families to cope with life stressors introduced by the disability. The ICF has been posited as a tool to develop specific health promotion activities in schools for youth with disabilities. ${ }^{8}$ Therefore, the purpose of this study was to using the ICF as a framework to examine parental perceptions of health and function among students with disabilities living in rural and urban areas using a sequential, mixed-method design.

\section{METHODS}

\section{Participants and Setting}

Parents served as key informants for their children, as some students with disabilities may not be able to accurately self-report certain data. The use of parents in this role is consistent with similar research with this population. ${ }^{21,22}$ Any parent of an adolescent(s) between the ages of 10 and 21 years with a medically diagnosed disability who received special education services as defined by IDEA $^{4}$ was eligible for participation in the study. This broad inclusion criteria was necessary to examine the complex nature of functionality among young people with disabilities, therefore parents of adolescents with either a cognitive and/or physical disability were included. The instruments used in the study contained measures that assessed functionality, providing a broader perspective of functionality among youth with a wide range of abilities.

As context can play a critical role in overall health, a single school district in one urban and one rural county in Georgia were selected for the study. Classifications for counties were based on the National Center for Health Statistics. ${ }^{23}$ Parents were recruited through schools and community-based organizations (CBOs) in each school district. Seventy-one parents of children with a disability completed surveys. Respondents were mostly female (Table 1), and a variety of ages are represented in the study sample (Table 1).

\section{Instrumentation}

The Comprehensive Parent Report Form of the (CHIP-CE) is a 76-item questionnaire measuring 5 domains of health: satisfaction, comfort, resilience, risk avoidance, and achievement. ${ }^{24}$ The CHIP-CE Parent Report form has been shown to be a valid and reliable measure of HRQOL among diverse populations 


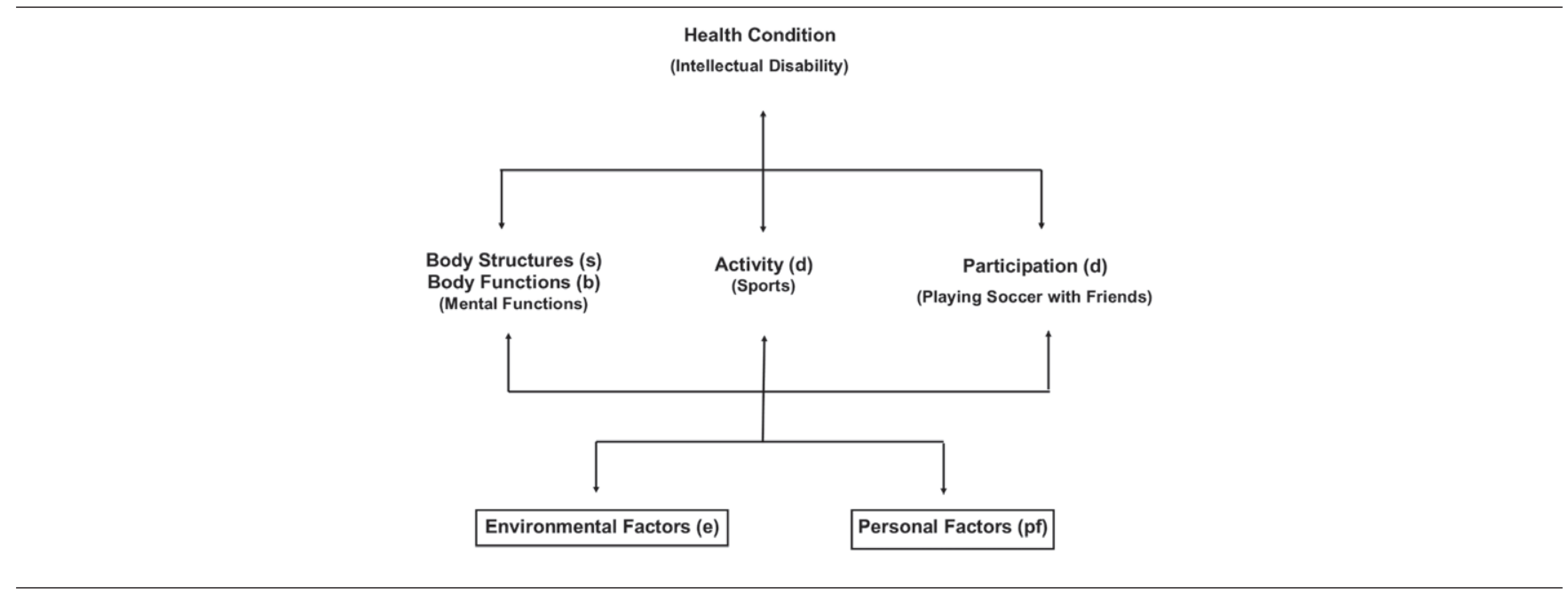

Table 1. Description of Sample Demographics $(\mathrm{N}=71)$

\begin{tabular}{|c|c|c|}
\hline & $\mathbf{N}$ & $\%$ \\
\hline \multicolumn{3}{|l|}{ Location } \\
\hline Urban & 29 & 40.85 \\
\hline Rural & 42 & 59.15 \\
\hline \multicolumn{3}{|l|}{ Sex* } \\
\hline Men & 6 & 8.57 \\
\hline Women & 64 & 91.43 \\
\hline \multicolumn{3}{|l|}{ Sex of child } \\
\hline Boys & 43 & 60.56 \\
\hline Girls & 28 & 39.44 \\
\hline \multicolumn{3}{|l|}{ Relation to child } \\
\hline Birth mother & 60 & 84.5 \\
\hline Adoptive mother & 2 & 2.82 \\
\hline Grandmother & 2 & 2.82 \\
\hline Birth father & 3 & 4.23 \\
\hline Other & 4 & 5.63 \\
\hline \multicolumn{3}{|l|}{ Grade level of child ${ }^{\dagger}$} \\
\hline Grade 3 & 1 & 1.45 \\
\hline Grade 4 & 2 & 2.9 \\
\hline Grade 5 & 4 & 5.8 \\
\hline Grade 6 & 8 & 11.59 \\
\hline Grade 7 & 15 & 21.74 \\
\hline Grade 9 & 2 & 2.9 \\
\hline Grade 10 & 5 & 7.24 \\
\hline Grade 11 & 2 & 2.9 \\
\hline Grade 12 & 4 & 5.8 \\
\hline Not in school & 26 & 37.68 \\
\hline
\end{tabular}

*One missing value.

†Two missing values.

between the ages of 6 and 18 years old. ${ }^{25,26}$ The instrument can be completed by parents with at least a fifth grade reading level in less than 20 minutes, and is appropriate for use among diverse populations. Among the domains of the CHIP-CE, reliability is moderate to high $(\alpha=0.79-0.88$; intraclass correlation coefficients $[\mathrm{ICC}]=0.71-0.85)$. Most items assess frequency and degree over the previous 4 weeks, using a Likert scale.
The Pediatric Outcomes Data Collection Instrument (PODCI) was originally developed by the American Academy of Orthopedic Surgeons and the Pediatric Orthopedic Society of North America to measure functional health outcomes for children and adolescents and has demonstrated good reliability and construct validity. ${ }^{27}$ The parent report version for adolescents contains 86 questions with 6 domains: upper extremity physical function, transfers/basic mobility, sports/physical function, pain/comfort, happiness, and global function. The instrument can be completed by parents in less than 20 minutes $^{28}$ and has demonstrated strong validity and reliability in diverse populations. $^{29,30}$ The instrument is scored using a standardized scale of 0 to 100 with scores in the mid-80s representing normative values of the general population. $^{31,32}$

An interview guide was developed based on the National Survey of Children with Special Health Care Needs (2009-2010). ${ }^{33}$ The guides covered questions specific to perceived challenges and facilitators to obtaining health and support services, coordinated care, decision-making, and transition. Probing and follow-up questions were developed to help enrich the qualitative data obtained during each in-depth interview.

\section{Procedures}

In the rural school district, potential parent participants were recruited by sending home consent forms and surveys via special education teachers. In the urban school district, parents were forwarded an email from a link to the online version of both the surveys. Follow-ups were sent to both urban and rural participants.

Participants who returned the survey were entered to win a drawing for one of $5 \$ 100$ gift cards. The last 
page of the survey contained a separate survey asking for parental participation in the second phase of the study, individual interviews. A total of 18 parents ( $\mathrm{N}=8$ rural; $\mathrm{N}=10$ urban), participated in individual, in-depth interviews. Each interview last approximately 60 to 90 minutes.

\section{Data Analysis}

Statistical analysis was performed using SPSS v. 21. Descriptive statistics were calculated for the domains scores of the CHIP and the subscales of the PODCI. We processed qualitative interviews following the refined ICF linking rules. ${ }^{34}$ As recommended, 2 independent researchers trained in the use of the ICF framework and linking rules independently coded each set of transcripts line by line using the ICF practice manual $^{35}$ and ICF-Browser ${ }^{36}$ as resources. If discrepancies occurred in coding or linking, a third researcher reviewed each code for the final decision on the most appropriate category linking. ${ }^{34}$ Similar to the methods used by Schiariti et al, ${ }^{37}$ we organized themes based on the ICF systematic coding system. ${ }^{38}$ Each theme was first assigned a letter with a corresponding ICF category: body structures (s), body functions (b), activity/participation (d), environmental factors (e), and personal factors (f). Themes were then assigned numerical numbers which corresponded to ICF levels of classifications based on specificity. More specific themes represented lower level (more detailed) themes or descriptions of health and functioning (Figure 2). Following the ICF manual, each item was coded and linked to the most specific level or code possible.

\section{RESULTS}

\section{Descriptive Statistics}

Descriptive statistics of the CHIP and PODCI domain scores are displayed in Table 2. The scores for the CHIP ranged from " 2 " to " 5 " on a 5-point scale. Among both urban and rural children, the lowest average score CHIP domain score was achievement while the highest average score was for risk-avoidance. Means on the standardized scores from the PODCI domains showed a wider range of values among urban and rural children. However, sports and physical functioning were the lowest domain scores and pain/comfort were the highest for both urban and rural children.

\section{Interviews}

Using the ICF as a guide, we identified 921 unique codes (316 for the rural and 605 for the urban). A majority of the codes (approximately 90\%) were third and fourth level ICF categories. Of the 921 codes, $60 \%$ were identified as environmental factors, $24.9 \%$ identified as activities and participation, 9\% identified as body functions, $5.9 \%$ identified as personal factors,
Figure 2. Coding Hierarchy by Level in the International Classification of Functioning, Disability, and Health

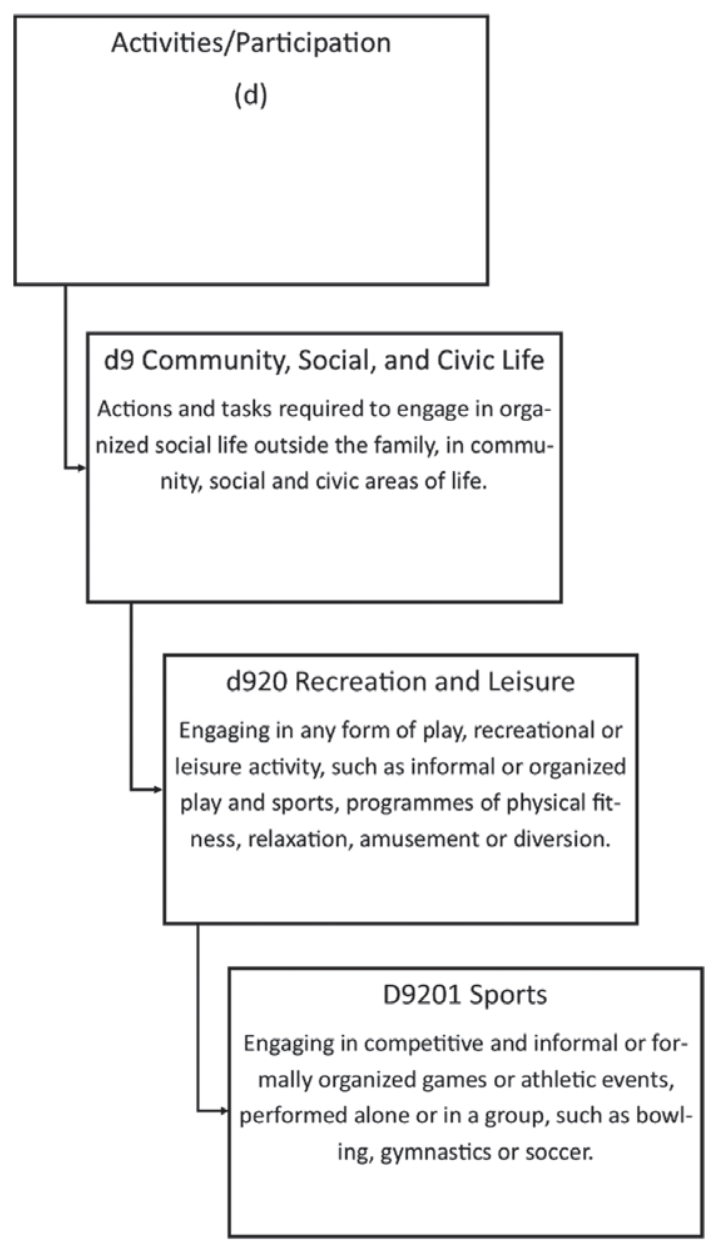

and less than $1 \%$ identified as body structures. The most commonly coded classification regardless of context was Environmental Factors. Category e5, services, systems and policies accounted for the highest number of codes in both rural and urban areas $(50 \%$ for urban and $58 \%$ for rural). The second most coded category fell under Environmental Factors category e3, support and relationships (23\% urban, 33\% rural). Activities and participation accounted for the second most coded classification in both contexts. In rural areas, the top 3 codes are linked to $\mathrm{d} 8$, major life areas $(20 \%)$, d 4 mobility ( $18 \%)$, and d5 self-care $(15 \%)$ under Activities and Participation and in urban areas d5 selfcare $(21 \%)$, d8 major life areas $(13 \%)$, and $\mathrm{d} 6$ domestic life $(13 \%)$. Table 3 provides frequency information for each ICF category/code.

\section{Environmental Factors}

Both rural and urban caregivers identified services, systems, and policies (e5) as a major factor influencing all other categories (ie, body function, activities, and 
Table 2. Descriptive Statistics for the CHIP and PODCI Domain Scores

\begin{tabular}{lll}
\hline & & M (SD) \\
\hline CHIP domain & & \\
Satisfaction & Urban & $3.50(.67)$ \\
& Rural & $3.90(.57)$ \\
Comfort & Urban & $4.04(.55)$ \\
& Rural & $4.10(.53)$ \\
Risk avoidance & Urban & $4.16(.52)$ \\
& Rural & $4.12(.61)$ \\
Resilience & Urban & $3.29(.56)$ \\
& Rural & $3.72(.42)$ \\
Achievement & Urban & $3.19(.63)$ \\
& Rural & $3.15(.83)$ \\
PODCl domain & & \\
Upper extremity & Urban & $68.17(30.25$ \\
& Rural & $86.26(26.7)$ \\
Transfer and basic mobility & Urban & $88.04(22.07)$ \\
& Rural & $87.75(28.43)$ \\
Sports and physical functioning & Urban & $60.88(28.29)$ \\
& Rural & $71.48(28.98)$ \\
Pain/comfort & Urban & $86.42(18.45)$ \\
& Rural & $87.22(17.25)$ \\
Happiness & Urban & $81.33(14.92)$ \\
Global functioning & Rural & $75.00(22.93)$ \\
& Urban & $75.75(19.06)$ \\
& Rural & $83.16(22.08)$ \\
\hline
\end{tabular}

CHIP, Child Health and IIIness Profile; PODCl, Pediatric Data Collection Instrument.

participation). In rural areas, most were coded as barriers.

e575 General Social Support Services, Systems, and Policies

I know of [support service name]... I mean I know that they have like a dance for the kids. But I don't know like what else they do. I mean, I know they do stuff per..., you know, throughout the year. Easter egg hunts they used to. I haven't got any notifications for a lot of stuff lately. So I don't know if that's teacher error or what.

e580 Health Services, Systems, and Policies

Okay, well he was getting that. And the therapist, the physical therapist thought that, um she had done all she could do...

Among urban caregivers, e5 coded items were viewed mostly as facilitators to supports that were needed. Education services, systems, and policies (e585) were coded more frequently by urban families and were key facilitators.

\section{e5853 Special Education Services}

... he's in the right school he has access to you know all the support system that he needs we don't worry about any of that anymore

In both rural and urban areas, e3 support and relationships was the second most frequently coded category under environment. A majority of codes were noted as facilitators regardless of context. One rural
Table 3. Frequency of ICF Levels by Classification

\begin{tabular}{|c|c|c|}
\hline ICF Classification and Levels & Rural & Urban \\
\hline \multicolumn{3}{|l|}{ Body structures } \\
\hline s1 Structures of nervous system & 4 & \\
\hline s2 The eye/ear related structures & 1 & \\
\hline \multicolumn{3}{|l|}{$\begin{array}{l}\text { s4 Structures of the cardiovascular } \\
\text { immunological/respiratory system }\end{array}$} \\
\hline $\begin{array}{l}\text { s5 Structures related to digestive, metabolic } \\
\text { and endocrine }\end{array}$ & 1 & \\
\hline s7 Structures related to movement & 2 & 2 \\
\hline \multicolumn{3}{|l|}{ Body functions } \\
\hline b1 Mental functions & 21 & 33 \\
\hline b2 Sensory functions and pain & 2 & 4 \\
\hline b3 Voice and speech functions & 2 & 5 \\
\hline b4 Functions of the cardiovascu- & & 7 \\
\hline lar/hematological/immunological/respiratory & & \\
\hline $\begin{array}{l}\text { b5 Functions digestive, metabolic and } \\
\text { endocrine systems }\end{array}$ & 2 & 6 \\
\hline b6 Genitourinary and reproductive & & \\
\hline $\begin{array}{l}\text { b7 Neuromusculoskeletal and movement } \\
\text { related functions }\end{array}$ & 1 & 6 \\
\hline b8 Functions of skin and related structures & & 1 \\
\hline \multicolumn{3}{|l|}{ Activities and participation } \\
\hline d1 Learning/applying knowledge & 9 & 19 \\
\hline d2 General tasks and demands & 6 & 6 \\
\hline d3 Communication & 3 & 11 \\
\hline d4 Mobility & 19 & 22 \\
\hline d5 Self-care & 16 & 39 \\
\hline d6 Domestic life & 15 & 25 \\
\hline d7 Interpersonal relationships & 13 & 21 \\
\hline d8 Major life areas & 21 & 25 \\
\hline d9 Community, social and civic life & 5 & 21 \\
\hline \multicolumn{3}{|l|}{ Environmental factors } \\
\hline e1 Products and technology & 7 & 42 \\
\hline $\begin{array}{l}\text { e2 Natural environment, human made } \\
\text { changes to environment }\end{array}$ & & 6 \\
\hline e3 Support and relationships & 62 & 86 \\
\hline e4 Attitudes & 6 & 48 \\
\hline e5 Services, systems and policies & 110 & 186 \\
\hline Personal & 1 & \\
\hline
\end{tabular}

parent spoke about other people in the child's life that have provided support.

\section{e398 Support and Relationships, other specified}

So there are people out there that they can reach out too. Not everybody want to take time to deal with a person or childlike[child's name], unlike many other kids because of their disability... there are peoples out there that reach out to them just as well they do people like me and you.

An urban parent discussed her role as an advocate for her child.

e310 Immediate Family

I advocate for mine... people say I have a gift of finding resources. I don't know that I have a gift of finding resources... I have a child that I love, more than anything in the world. And I want him to not want for anything. 
Among urban caregivers, codes classified as barriers were linked to e4, attitudes. Other peoples' perceptions of the child seemed to impact the parental perception of their child and the families' quality of life.

\section{e460 Societal Attitudes}

It's like, wherever you go, people are staring at you... You really get tired of that. As if he doesn't belong... Um, make no mistake, I don't care if they look. I think that, what I've learned is a lot of people don't understand.

In other cases, an immediate family member's attitude caused increased stress and most often related to a parent or grandparent denying the child's diagnosis.

\section{e410 Individual Attitudes of Immediate Family Member}

So I would argue with him but I would always take her to get medical treatment. And for some reason I can't understand. It was like he was kind of in denial, you know. And that's frustrating so we ended up getting a divorce, not totally because of her situation but it's very stressful because there was a lot of stuff.

\section{Activities and Participation}

Major life areas (d8) and self-care (d5) were frequently coded in both urban and rural families.

\section{d540 Dressing}

... I believe he's learning how to tie his shoes. They said he wasn't gonna be able to do that... He has got everything down to a pin, except for that one... I see progression in my son.

\section{d825 Vocational and d830 Higher Education}

I'm still hopeful. We were just talking last night. We're still hopeful that there will be postsecondary for [Child's Name], whether it's a college setting or it's online. He loves to learn so I'm going to continue putting that out in front of him as long as he's willing to accept it.

Though some differences in coding existed between urban and rural families, similarities were more common. One difference to note between contexts is the role environmental factors served. Even though e5 was the most common code in both contexts, in rural areas the e5 levels served as barriers. In urban areas most e5 codes were facilitators. Urban families were more likely to identify category e4 as barriers to the other classifications. This category represented only $3 \%$ of the codes in rural families.

\section{DISCUSSION}

The purpose of this study was to examine parent perspectives on health and functioning using a sequential, mixed methods design. The purpose of the survey was to both capture descriptive data while purposefully recruiting parents for individual interviews. Survey results suggested both urban and rural respondents reported relatively low levels of achievement, on average, when compared to levels of risk avoidance and comfort. This finding suggests that youth who engaged in "high risk" behavior were less likely to be successful in social contexts, as questions in the achievement domain focused on performance in school and peer interaction. This is supported by similar findings, indicating that social acceptance can be a key predictor of happiness and success. ${ }^{39}$ In addition, low levels of achievement and comfort suggest that children with poor physical health (eg, "In the past 4 weeks, how often did your child feel too sick to play outside?") were less likely to achieve success in school and in other social contexts. Houtrow et $\mathrm{al}^{40}$ found that youth with physical limitations faced many barriers to engagement in with the school and community.

Results of the PODCI domain scores indicated greater variation among urban and rural respondents. Differences in the functional domains or upper extremity function and sports and physical functioning were likely due to the differences in the physical capabilities of each child. Even though rural children reported higher values in these areas related to function, scores were similar in transfer and basic mobility. Survey questions related to transfer and mobility contained 5 questions which could be mediated by the use of an assistive device, with only one question asking the frequency which assistive devices were used. This indicates that urban respondents may have access to assistive devices that enable them to overcome a lack of function in the upper or lower extremity. Children with disabilities in rural areas often have less access to physical and occupational therapy services and therefore often fail to utilize these specialized services which would provide them access to assistive devices. ${ }^{41}$ In all subscales but Happiness, rural children's scores were approximately the same or higher than their urban peers.

Although little research has been done examining differences between rural and urban youth in happiness or other psychosocial measures, the results from the interviews indicate that the environment plays a significant mediating factor in many of the domains captured in the survey. Of the 921 codes, $60 \%$ were identified as environmental barriers or facilitators with approximately $25 \%$ identified as activities and participation. This is consistent with a previous study by Anaby et $\mathrm{al}^{42}$ which found that the environment accounted for $50 \%-64 \%$ of variation in participation in daily activities in the home, school, and community. The questions from both the CHIP and PODCI surveys 
primarily asked respondents to rate their child's ability in activities of daily living such as lifting a book, pouring a glass of milk, walking one block, or participating in a game or sport. The ICF would classify each of these as either an activity or participation. Rural parents stated that a lack of access to health (e580, health services, systems, and policies) and support (e575, general social support services, systems, and policies) services often resulted in barriers to participating in social activities and receiving specialized services. Among urban families, most codes under the broader category of services, systems and policies (e5) served as facilitators to activity and participation. This is consistent with other studies which have found that children in rural areas have less access to recreational opportunities and therapy services. ${ }^{41,43}$

In both urban and rural areas, psychosocial environmental factors served as both barriers and facilitators to the quality of life and function of the family unit. Support and relationships (e3) was frequently reported as a facilitator for activity and participation among urban and rural families. These supportive relationships were from both immediate family (e310) and others (398). Social support can be a powerful factor in the well-being and resilience of the family. ${ }^{44}$ Parents who receive more support from their spouse and other family members report a higher quality of life for the whole family. ${ }^{45}$ However, the attitudes of immediate family members also served as a stressor in some cases. Caring for a child with a disability requires a specific amount of time, physical energy, and mental stamina, and additional strain from other family members can negatively many work and life outcomes of the caregiver. ${ }^{46}$ Societal attitudes also caused stressed for parents and possibly served as a barrier to family participation in the community. Parents are very aware of negative attitudes toward their child with a disability and the potential for harm they may cause. Over a 3-year period, a cohort of parents caring for a child with a disability reported that rates of peer victimization and negative attitudes between $21 \%$ and $30 \% .{ }^{47}$ Although these parents experienced stress when faced with these societal attitudes, these families were unknowingly promoting change. There is a substantial body of research that indicates that contact between children without a disability and an individual with a disability can greatly improve their attitudes toward disability. ${ }^{48}$

Life skills and activities associated with self-care were perceived as very important skills by parents. Parents have often identified activities related to selfcare as the most important for their child with a disability. ${ }^{49}$ As parents have a finite amount of energy and time to care for their child with a disability, a child taking over any aspect of their own care could greatly reduce the demands and stress of the parent. ${ }^{46}$ Families were also hopeful for postsecondary opportunities for their child with a disability. There is a great deal of variation in experiences in employment and schooling after high school among young adults with disabilities, which is often related to the significance of their impairment. ${ }^{50}$ Children with significant disabilities often have little to no access to postsecondary educational opportunities. ${ }^{51}$ It is vital that all individuals have equal opportunities to have a meaningful day regardless of their abilities. There is a crucial need to change social and cultural norms to improve the transition experience for youth with disabilities. $^{52}$

\section{Limitations}

A major limitation of this study was the lack of quantitative data. In addition, the versions of data collection instruments were not identical for all participants. Most of the parents in the urban area answered their questionnaires online whereas rural participants received a paper copy of the survey. Another limitation was the small sample size, with a reasonably large range in age and type of disability. Although the results of the survey are informative, they should not be generalized to a specific disability population and should be considered specific to the study sample. The primary purpose of the survey was to serve as a recruitment tool for interview participants and to provide descriptive information for the sample.

A strength of this study was the reliance on schools and $\mathrm{CBOs}$ to recruit participants. The approximate number of families contacted in both contexts by schools and agencies was 1300; however, the researchers were dependent on listservs created by schools and CBOs. Therefore, calculating a definite response rate is difficult. Listservs are useful communication tools but they require current contact information from those using the mass e-mail communication list. A strength of this study was the use of individual, in-depth interviews. These provided rich, insightful data into the lives of parents living for a child with a disability. An additional strength was the use of the ICF as a theoretical framework and as a coding tool for interviews. The ICF can serve many purposes and can be a useful tool for school health practitioners. Though the results of this study may not be generalized to other disability populations, results provide key insight into the role of the environment in mediating activity and participation and its relation to health among parents caring for a child with a disability.

\section{Conclusions}

Although some disparities between urban and rural families were evident, the commonalities were unexpected. This should highlight the significant barriers that families caring for a child with a disability 
face, regardless of context. Although urban parents perceived environmental factors as a facilitator for activities and participation, all parents reported that their child lacked sufficient and equitable opportunities for activity and participation.

\section{IMPLICATIONS FOR SCHOOL HEALTH}

School-health practitioners should note the potential of the ICF to plan programming for youth with disabilities. The ICF provides a comprehensive framework to plan, implement, and adapt programming to meet the needs of children in the school health curriculum. In addition, school health practitioners in all areas can appreciate the experiences of parents in the caring for their child. School-based health educators, physical therapists, occupational therapists, and social service professionals must understand the mediating role of the environment in activity and participation of the youth they serve. Tools such as community-mapping and environmental scans for services can provide key insight as practitioners implement programs that will transfer from school to the home and community.

\section{Human Subjects Approval Statement}

This study was approved and completed in according with the Institutional Review Board at Georgia Southern University.

\section{REFERENCES}

1. Basch CE. Healthier students are better learners: a missing link in school reforms to close the achievement gap. $J$ Sch Health. 2011;81(10):593-598.

2. Michael SL, Merlo CL, Basch CE, Wentzel KR, Wechsler H. Critical connections: health and academics. J Sch Health. 2015;85(11):740-758.

3. Basch CE. Healthier students are better learners: high-quality, strategically planned, and effectively coordinated school health programs must be a fundamental mission of schools to help close the achievement gap. J Sch Health. 2011;81(10):650-662.

4. Individuals with Disabilities Education Act (IDEA). 20 U.S.C. § 1400; 2004

5. Snyder TD, de Brey C, Dillow SA. Digest of Education Statistics 2015 (NCES 2016-014). Washington, DC: National Center for Education Statistics, Institute of Education Sciences, U.S. Department of Education; 2016.

6. Raman SR, Boyce WF, Pickett W. Associations between adolescent risk behaviors and injury: the modifying role of disability. J Sch Health. 2009;79(1):8-16.

7. Everett Jones S, Lollar DJ. Relationship between physical disabilities or long-term health problems and health risk behaviors or conditions among US high school students. $J$ Sch Health. 2008;78(5):252-257.

8. Hollar D. Risk behaviors for varying categories of disability in NELS:88. J Sch Health. 2005;75(9):350-358.

9. World Health Organization. Early Childhood Development and Disability: A Discussion Paper. Geneva, Switzerland: WHO; 2012.

10. Cornwell L, Hawley SR, St Romain T. Implementation of a coordinated school health program in a rural, low-income community. J Sch Health. 2007:77(9):601-606.
11. Walker A, Alfonso ML, Colquitt G, Weeks K, Telfair J. "When everything changes": parent perspectives on the challenges of accessing care for a child with a disability. Disabil Health J. 2016;9(1):157-161.

12. Baller JB, Barry CL. State variation in school-based disability services financed by Medicaid. J Disabil Policy Stu. 2016;27(3):148-157.

13. Law M, Petrenchik T, King G, Hurley P. Perceived environmental barriers to recreational, community, and school participation for children and youth with physical disabilities. Arch Phys Med Rehab. 2007;88(12):1636-1642.

14. Sinclair LB, Tanenhaus RH, Courtney-Long E, Eaton DK. Disability within US public health school and program curricula. J Public Health Man. 2015;21 (4):400-405.

15. Hinckson EA, Dickinson A, Water T, Sands M, Penman L. Physical activity, dietary habits and overall health in overweight and obese children and youth with intellectual disability or autism. Res Dev Disabil. 2013;34(4):1170-1178.

16. Halfon N, Houtrow A, Larson K, Newacheck PW. The changing landscape of disability in childhood. Future Child. 2012;22(1):1342.

17. Beckung E, White-Koning $M$, Marcelli $M$, et al. Health status of children with cerebral palsy living in Europe: a multi-centre study. Child Care Hlth Dev. 2008;34(6):806-814.

18. World Health Organization. Towards a Common Language for Functioning, Disability and Health: The International Classification of Functioning, Disability and Health. Geneva, Switzerland: WHO; 2002.

19. World Health Organization. Implementing the Merger of the ICF and ICF-CY: Background and Proposed Resolution for Adoption by the World Health Organization Family of International Classification Council. Geneva, Switzerland: WHO; 2012.

20. Heiman T. Parents of children with disabilities: resilience, coping, and future expectations. J Dev Phys Disabil. 2002;14(2):159171.

21. Woodward JF, Swigonski NL, Ciccarelli MR. Assessing the health, functional characteristics, and health needs of youth attending a noncategorical transition support program. $J$ Adolescent Health. 2012;51(3):272-278.

22. Simeonsson RJ, Carlson D, Huntington GS, McMillen JS, Brent JL. Students with disabilities: a national survey of participation in school activities. Disabil Rehabil. 2001;23(2):49-63.

23. Ingram DD, Franco SJ. National Center for Health Statistics urban-rural classification scheme for counties. Vital Health Stat. 2012;2(154):1-65.

24. Riley AW, Forrest CB, Starfield B, Rebok GW, Robertson JA, Green BF. The parent report form of the CHIP: child edition. Med Care. 2004;42(3):210-220.

25. Riley AW, Coghill D, Forrest CB, et al. Validity of the healthrelated quality of life assessment in the ADORE study: parent report form of the CHIP-child edition. Eur Child Adoles Psy. 2006;15(Suppl 1):I63-I71.

26. Riley AW, Forrest CB, Starfield B, Rebok GW, Robertson JA, Green BF. The parent report form of the CHIP-child edition: reliability and validity. Med Care. 2004;42(3):210-220.

27. Daltroy LH, Liang MH, Fossel AH, Goldberg MJ, Grp POID. The Pediatric Orthopaedic Society of North America Pediatric Musculoskeletal Functional Health Questionnaire: report on reliability, validity, and sensitivity to change. J Pediatr Orthoped. 1998;18(5):561-571.

28. Pencharz J, Young NL, Owen JL, Wright JG. Comparison of three outcomes instruments in children. $J$ Pediatr Orthoped. 2001;21(4):425-432.

29. do Monte FA, Ferreira MN, Petribu KC, et al. Validation of the Brazilian version of the pediatric outcomes data collection instrument: a cross-sectional evaluation in children and adolescents with juvenile idiopathic arthritis. BMC Pediatr. 2013;13:177. https://doi.org/10.1186/1471-2431-13-177. 
30. Wren TA, Sheng M, Bowen RE, et al. Concurrent and discriminant validity of Spanish language instruments for measuring functional health status. J Pediatr Orthoped. 2008;28(2):199-212.

31. Haynes RJ, Sullivan E. The Pediatric Orthopaedic Society of North America Pediatric Orthopaedic Functional Health Questionnaire: an analysis of normals. J Pediatr Orthoped. 2001;21(5):619-621.

32. Hunsaker FG, Cioffi DA, Amadio PC, Wright JG, Caughlin B. The American Academy of Orthopaedic Surgeons outcomes instruments: normative values from the general population. $J$ Bone Joint Surg Am. 2002;84-A(2):208-215.

33. Bramlett $\mathrm{MD}$, Blumberg SJ, Ormson AE, et al. Design and operation of the National Survey of Children With Special Health Care Needs, 2009-2010. Vital Health Stat. 2014;(57):1271.

34. Cieza A, Fayed N, Bickenbach J, Prodinger B. Refinements of the ICF linking rules to strengthen their potential for establishing comparability of health information. Disabil Rehabil. 2016:1-10. https://doi.org/10.3109/09638288.2016.1145258.

35. World Health Organization. How to Use the ICF: A Practical Manual for Using the International Classification of Functioning, Disability and Health (ICF). Exposure Draft for Comment. Geneva, Switzerland: WHO; 2013.

36. World Health Organization. ICF Browser. Available at http:// apps.who.int/classifications/icfbrowser/.

37. Schiariti V, Sauve K, Klassen AF, O’Donnell M, Cieza A, Masse LC. 'He does not see himself as being different': the perspectives of children and caregivers on relevant areas of functioning in cerebral palsy. Dev Med Child Neurol. 2014;56(9):853-861.

38. World Health Organization. International Classification of Functioning, Disability and Health. Version for Children and Youth. Geneva, Switzerland: WHO; 2004.

39. King GA, Cathers T, Polgar JM, MacKinnon E, Havens L. Success in life for older adolescents with cerebral palsy. Qual Health Res. 2000;10(6):734-749.

40. Houtrow A, Jones J, Ghandour R, Strickland B, Newacheck P. Participation of children with special health care needs in school and the community. Acad Pediatr. 2012;12(4):326-334.

41. McManus BM, Lindrooth R, Richardson Z, Rapport MJ. Urban/rural differences in therapy service use among Medicaid children aged 0-3 with developmental conditions in Colorado. Acad Pediatr. 2016;16(4):358-365.

42. Anaby D, Law M, Coster W, et al. The mediating role of the environment in explaining participation of children and youth with and without disabilities across home, school, and community. Arch Phys Med Rehabil. 2014;95(5):908-917.

43. Buttimer J, Tierney E. Patterns of leisure participation among adolescents with a mild intellectual disability. $J$ Intellect Disabil. 2005;9(1):25-42.

44. Armstrong MI, Birnie-Lefcovitch S, Ungar MT. Pathways between social support, family well being, quality of parenting, and child resilience: what we know. J Child Fam Stud. 2005; 14(2):269-281.

45. Cohen SR, Holloway SD, Dominguez-Pareto I, Kuppermann M. Receiving or believing in family support? Contributors to the life quality of Latino and non-Latino families of children with intellectual disability. J Intellect Disabil Res. 2014;58(4):333-345.

46. Li A, Shaffer J, Bagger J. The psychological well-being of disability caregivers: examining the roles of family strain, family-to-work conflict, and perceived supervisor support. $J$ Occup Health Psychol. 2015;20(1):40-49.

47. Son E, Parish SL, Peterson NA. National prevalence of peer victimization among young children with disabilities in the United States. Child Youth Serv Rev. 2012;34(8):1540-1545.

48. MacMillan M, Tarrant M, Abraham C, Morris C. The association between children's contact with people with disabilities and their attitudes towards disability: a systematic review. Dev Med Child Neurol. 2014;56(6):529-546.

49. Chiarello LA, Palisano RJ, Maggs JM, et al. Family priorities for activity and participation of children and youth with cerebral palsy. Phys Ther. 2010;90(9):1254-1264.

50. Grigal M, Neubert DA. Parents' in-school values and post-school expectations for transition-aged youth with disabilities. Career Dev Transit Except Individ. 2004;27(1):65-85.

51. Neubert DA, Moon MS, Grigal M. Activities of students with significant disabilities receiving services in postsecondary settings. Educ Train Dev Disab. 2004;39(1):16-25.

52. Trainor AA. Using cultural and social capital to improve postsecondary outcomes and expand transition models for youth with disabilities. J Spec Educ. 2008;42(3):148-162. 